\title{
AN EVOLUTIONARY APPROACH TO EMERGENCE AND SOCIAL CAUSATION
}

\author{
BY \\ NUNO MARTINS ${ }^{1}$ \\ Portuguese Catholic University \\ nmartins@porto.ucp.pt
}

\begin{abstract}
Rom Harré criticizes critical realism for ascribing causal powers to social structures, arguing that it is human individuals, and not social structures, that possess causal powers, and that a false conception of structural causation undermines the emancipatory potential of critical realism. I argue that an interpretation of the category of process as the spatio-temporalization of the category of structure, which underpins much evolutionary theory, provides the conceptual tools to explain how the critical realist transformational model of social activity can escape from Harré's criticism, leading to a general conception of social development within which various types of evolutionary processes can be identified as particular cases. I then argue that Tony Lawson's PVRS model provides an evolutionary perspective that enables the conceptualization of coercive power as selective pressure.
\end{abstract}

Key words: causation; evolution; power; process; PVRS model; structure

\section{Introduction}

Rom Harré argues that the transformational model of social activity is a useful heuristic or explanatory model, but a false representational or descriptive model, since it falsely portrays social structures as entities endowed with causal

\footnotetext{
1 Faculty of Economics and Management, Portuguese Catholic University, Rua Diogo Botelho, 1327, 4169-005 Porto, Portugal. Nuno Ornelas Martins is a Lecturer in Economics at the School of Economics and Management of the Portuguese Catholic University, Porto. He completed a PhD in Economics at the University of Cambridge in 2006, and is a member of the Cambridge Social Ontology Group. His research interests include critical realism, capabilities and human development, the Cambridge economic tradition, and social economics.

For most helpful comments I am very grateful to Ismael Al-Amoudi, John Latsis, the participants of the Oxford Seminar for Conventions and Rules, and the anonymous referees of this journal.
} 
powers. Harré argues that this error constrains the emancipatory potential of critical realism, which is developed in Roy Bhaskar's theory of explanatory critique. ${ }^{2}$ I will argue that an interpretation of emergence drawing upon the category of process clarifies the nature of structural causation in critical realism, and can be fruitfully combined with Aristotle's four causes.

A particular type of structural causation that is central to the theory of explanatory critique, and to the emancipatory potential of critical realism that Harré questions, concerns the exercise of coercive power through social structures that constrain human well-being. In order to address this particular type of structural causation, a specification of the transformational model of social activity in terms of an evolutionary process will be provided drawing upon Tony Lawson's PVRS (Population-Variety-Reproduction-Selection) model. This evolutionary approach will also help to further elaborate Aristotle's category of final cause.

An important issue to address in this regard concerns the appropriateness of evolutionary models in social theory. It is often argued that in social theory, biological analogies will, in general, lead to what Harré calls a heuristic or explanatory model, but not a representational or descriptive model, raising also the problem of the appropriateness of the biological analogy used. I will argue that many of the problems commonly associated with evolutionary theory spring from the particular way in which evolutionary models are specified, where explanatory structures pertain to theories, and that Lawson's PVRS model, where explanatory structures are a property of reality, and not of the evolutionary theories that attempt to capture reality, provides a solution to these problems, rendering the PVRS model applicable to study important aspects of structural causation.

I start by comparing Harré's perspective with critical realism in $§ 2$. In $§ 3$ I provide an account of emergence based upon the category of process, and draw its implications for Harré's critique of the transformational model of social activity. In \$4 I argue that Aristotle's four causes can be fruitfully combined with the categories of process, evolution, emergence and structural causation elaborated before, and in $\$ 5$ the relation of Aristotle's final cause to evolutionary theory will be discussed in more detail. In $\$ 6$ I argue for a realist approach to evolutionary theory, and Lawson's PVRS (PopulationVariety-Reproduction-Selection) model will be described in $\S 7$. In $\S 8$ the main characteristics of the PVRS model, and the role of variety-generating mechanisms, replication mechanisms and selection mechanisms, will be further elaborated, after which some concluding remarks will follow.

\footnotetext{
$2 \quad$ Bhaskar 1986.
} 


\section{Discourse and Reality}

Harré distinguishes two levels of scientific discourse: level 1, where 'nominal expressions refer to observables, that is to relevant objects, properties, structures and processes that are presented among and selected from the many features of the sensory domain', and level 2, where 'nominal expressions refer to unobservables, imaginary objects, properties, structures and processes that have not yet been observed'. ${ }^{3}$ He notes that level 1 propositions lead to descriptive or representational models, while level 2 propositions lead to explanatory or heuristic models. Explanatory or heuristic models provide intelligibility to a scientific discourse, while descriptive or representational models provide not only intelligibility, but also plausibility, since the agentive entities depicted in descriptive or representational models (the bearers of causal powers) can reasonably be seen as belonging to the actual world. Harré argues:

The structural cycle, the 'double structure thesis' à la Bhaskar ([1979] 1998), is no doubt respectable as a heuristic model, but fallacious as a representational model. Human development does not come about from the influences of social structure on the nascent human being, but by interpersonal processes described so brilliantly by Lev Vygotsky (1978: chapter 4). People become members of a society, another metaphor with dangerous edges, by their Vygotskian origins as they acquire competence in practices recognized as correct in their local culture, that is acquire grammars, pick up schemata, scripts and so on, and are trained in good habits. Using these skills they do not produce structures, but a rich, interconnected mesh of meaningful exchanges. To collect up a set of rules and conventions as an institution is a harmless and useful classificatory device, so long as we do not slip into ascribing causal powers to it. ${ }^{4}$

Harré concludes the following concerning the emancipatory potential of critical realism:

[Human beings] can come to realize that the constraints that society seems to place upon their pursuit of worth are grammatical, in the sense that Ludwig Wittgenstein gave to that term ... All we have to do is to show people that they are trapped in the silken but fragile shrouds of a pattern of discourse conventions. Yet how deeply they resist these demonstrations! This resistance is instanced not only by creationists, religious fundamentalists of many faiths, patriots, fan clubs, Freudians and all sorts of others but the old style Critical Realists themselves! To go into this matter requires the help of Ludwig Wittgenstein and his conception of the hinges on which the doors of life turn (Wittgenstein, 1975) - fundamental practices that though they could be different, constitute and regulate forms of life. These forms of life are the contexts in which personal and social identities are formed. ${ }^{5}$

3 Harré 2009, 131.

4 Harré 2009, 138-9.

5 Harré 2009, 142, original emphasis. 
A key difference between Harré and critical realism is that for critical realism, rules and conventions are not just a useful classificatory device, but a constituent of reality. To think otherwise would be to reduce an ontological claim to an epistemological claim. As Bhaskar notes, referring also to Wittgenstein:

Wittgenstein said in a famous phrase that it is sufficient to talk only about the network, we do not have to talk about what the network describes. What my argument did was show that this was a fallacy. In showing that it was a fallacy I opened the way for rational arguments about ontology including the new ontology that I argued was necessary for science in A Realist Theory of Science. ${ }^{6}$

Since Harré and Bhaskar refer to Wittgenstein in the citations above, it will perhaps be useful to use the example of Wittgenstein himself to clarify this difference between Harré and critical realism:

Let us imagine a white surface with irregular spots on it. We then say that whatever kind of pictures these make, I can always approximate as closely as I wish to the description of it by covering the surface with a sufficiently fine square mesh, and then saying of every square whether it is black or white. In this way I have imposed a unified form on the description of the surface. The form is optional, since I could have achieved the same result by using a net with a triangular or hexagonal mesh. Possibly the use of a triangular mesh would have made the description simpler: that is to say, it might have been that we could describe the surface more accurately with a coarse triangular mesh than with a fine square mesh (or conversely), and so on. The different nets correspond to different systems for describing the world ... (the net might also consist of more than one kind of mesh: e.g. we could use both triangles and hexagons). The possibility of describing a picture like the one mentioned above with a net of a given form tells us nothing about the picture (for that is true of all pictures). But what does characterize the picture is that it can be described completely by a particular net with a particular size of mesh. ${ }^{7}$

We can say that while for Harré social structures exist in the theory being used (the 'net'), for critical realism social structures are part of the very nature of reality (the 'spots on the surface'). In Wittgenstein's Philosophical Investigations, as in the passage from the Tractatus above, the idea of a tension between theory and reality is also present (but language-games now play the role of the 'net', and ordinary language is the 'spots on the surface' being studied):

Our clear and simple language-games are not preparatory studies for a future regularization of language - as it were first approximations, ignoring friction and air-resistance. The language-games are rather set up as 'objects

6 Bhaskar 2007, 198.

7 Wittgenstein 1961, 138-9, original emphasis. 
of comparison' which are meant to throw light on the facts of our language by way not only of similarities, but also of dissimilarities. For we can avoid ineptness or emptiness in our assertions only by presenting the model as what it is, as an object of comparison - as, so to speak, a measuring-rod; not as a preconceived idea to which reality must correspond. (The dogmatism into which we fall so easily in doing philosophy. $)^{8}$

An analysis of Wittgenstein's contributions is beyond the scope of this paper, and the above quotes are meant only to illustrate the differences between Harré and critical realism. Nevertheless, one cannot help noting how Wittgenstein rejects the idea that reality must correspond to a particular theory that is used 'as an object of comparison' when studying reality, and that Wittgenstein's example, by presupposing a contrast between theory and reality, already presupposes both ontological realism and epistemological relativism.

Wittgenstein was very concerned with pointing out how we often make a mistake, which is that ' $[\mathrm{w}] \mathrm{e}$ predicate of the thing what lies in the method of representing it'. ${ }^{9}$ But one must also avoid the converse mistake, of circumscribing predicates only to the method of representing a thing, failing to address the things we are describing - the epistemic fallacy. As Bhaskar argues:

[T] he critic might inquire as to how you could ever establish an ontological conclusion, because this would involve making a claim about the world which in some way you have removed from its ground, its epistemological premises. You can't talk about things in themselves apart from our modes of knowing them. This is a very insidious line of reasoning and it is very important to see what is wrong with it - because if you can't establish any conclusion, about anything, apart from our way of proving it or establishing it, then you can't have any local or separate or particular knowledge, the only knowledge you can have is of the whole, and indeed the process of the whole. So if we are going to have knowledge of sub-totalities, if we are going to have knowledge of particular things, you must be able to detach the conclusions of some epistemic investigation from the epistemic investigation, and of course this is what we do in science. If we couldn't do it then whenever we wanted to say something (about the world) we would have to repeat all our supporting procedures, that is, our whole method of establishing it. So if we are going to have any separable knowledge, we are going to have to allow ontological conclusions from epistemological premises or assumptions and say that they are sui generis valid. ${ }^{10}$

If we accept both ontological realism and epistemological relativism, as critical realism does, we have a conception where (our production of) knowledge

8 Wittgenstein 1963, §130-1.

9 Wittgenstein 1963, $\$ 104$.

10 Bhaskar 2007, 193. 
progresses through the tensions between our epistemological concepts and the ontological structure of reality that we intend to analyse, that is, through contrasts that demand explanation. ${ }^{11}$ These tensions or contrasts lead to a continuous dialectic between our methods and concepts on the one hand, and the underlying reality on the other hand. But, as Bhaskar notes, science presupposes the possibility of detaching conclusions, as ontological claims, from the epistemological context. And so does the possibility of emancipation. As Nick Hostettler argues:

Enshrining errors and absences in 'legislative' conceptions reinforces tendencies towards stasis. By exposing them in the way he does, Wittgenstein makes a contribution to the possibility of realizing change. However, a conception of philosophy as purely deconstructive obscures the extent to which it entails descriptive and evaluative philosophy and simultaneously closes down the possibility of actively engaging in reconstructive philosophy. All three modes of philosophy are internally related in that each does require the other in practice. ${ }^{12}$

Harré is surely right to say that language and grammar (in Wittgenstein's sense) play an important role in constraining human well-being, but to the extent that language plays such a role, it acts in fact as a real causal force, and we need not just deconstructive, but also constructive and evaluative philosophy, to address these problems. Language can be seen both as an object to analyse, and as a means of analysis, and thus can be seen in both an ontological and epistemological perspective (hence, Wittgenstein's language games are an example of a means of analysis used to study a given object of analysis, namely ordinary language).

\section{Process, Emergence and Causation}

Harré's criticism springs from the fact that he distinguishes various fundamental levels for each scientific discourse with their own basic agents, advocating that human beings are the basic agent in social sciences, and the only social entity endowed with causal powers. This means that in the social realm, only human beings constitute what Harré and Madden call powerful particulars. ${ }^{13}$ Harré and Madden suggest a distinction between two types of particulars, Parmenidean particulars, which are characterized by their causal powers, and Aristotelian particulars, which allow for partial changes in their structure without losing their identity. This view of active powerful particulars

11 On which see also Lawson 1997, 199-226, and also Lawson 2003, 79-109.

12 Hostettler 2000, 27.

13 Harré and Madden 1975. 
contrasts with an atomistic conception where passive particles, for example atoms in a void, are the most fundamental entities in reality, the latter view going back to Democritus.

In the atomistic conception the explanation of reality at the level of passive atoms and void, which are the most fundamental level of reality in terms of which higher level processes, for example processes of energy transfer, are explained. However, as Brown and Harré note, the advances in physics in the last century suggest that at the supposedly most fundamental level we find again processes of energy transfer, such as quantum fields. ${ }^{14}$ In this sense, the fundamental level would not be constituted by atoms and void, or any type of fundamental particles, but by a complex hierarchy of interrelated processes.

Effectively, the supposedly fundamental level is characterized by internally related networks of positions, endowed with causal powers, through which various types of energy are transferred. Furthermore, it is not just subatomic particles, but also atoms, molecules, cells, living beings, and societies, that can all be seen as networks of positions. These networks, seen as spatial totalities wherein the behaviour of a given part cannot be understood without understanding the behaviour of the other parts, constitute the intrinsic structure of entities. Because these entities are intrinsically dynamic, that is, we cannot understand the current behaviour of the entity without knowing something of how it changes through time, the category of totality must be applied not only to space, but to time, leading to the notion of process, which can be seen, as Bhaskar suggests, as the spatio-temporalization of the notion of structure..$^{15}$

Hence, an atom is a structured process emergent from sub-atomic relations of energy transfer, while a molecule is a structured process emergent from atomic interaction, a cell is a structured process emergent from molecular interaction, a human being is a structured process emergent from cellular interaction, and societies are a structured process emergent from human interaction. This hierarchy of structured processes leads us to the critical realist emergent conception of a stratified reality.

Once we find structured processes, and not atoms and void, as the fundamental ontological organization of reality, there is no reason to neglect the causal role of structures other than physical structures, like chemical, biological or social structures. As Mark Bickhard argues, much inspired by the evolutionary theorist Donald Campbell, in this conception we obtain a stratified conception of reality, with each level characterized by a given pattern of organization. ${ }^{16}$ This is a conception that underpins the work of evolutionary

14 Brown and Harré 1988.

15 Bhaskar 1993.

16 Bickhard 2000; see also Whitehead 1929. 
theorists like Donald Campbell. ${ }^{17}$ However, as Bhaskar notes, the conception of authors such as Campbell, like the work of many evolutionary theorists, although very important in order to challenge the deductivist structure of scientific theories, still took structures to be a property of theories, and not of reality. ${ }^{18}$

Furthermore, as Bhaskar notes, the higher-level emergent phenomena may be formed by a superposition on the lower level - the case Bhaskar designates as superstructuration - or by a intraposition within the lower level - the case Bhaskar names as intrastructuration, in which the higher-level entities become constitutive of the lower-level phenomena, generating an internally related process that acts as a totality. ${ }^{19}$ Under this perspective, reality is a complex hierarchical process where higher-level entities are constituted by, and may be constitutive of, lower-level entities, in a deeply interconnected process.

Although Harré argues that powerful particulars are active entities, endowed with causal powers, and not passive particles, Harré seems to still allow for the existence of a fundamental level, from which supervenient or epiphenomenal entities arise, where higher-level processes, such as processes of energy transference between entities, can be explained in terms of the interaction of lower-level entities. This is why for Harré only agents, and not the structures they generate, can be described or represented as real, where structures could only be a property of theories in any case. However, once we locate structures in a dynamic reality, the most fundamental category is not a particle or any type of particular, but rather a structured process.

In the conception of Harré and Madden, on the other hand, reality is ascribed only to entities that are clearly delimitated, or individuated, namely powerful particulars, which are active beings in virtue of their intrinsic structure. The problem raised by the conception of Harré and Madden is that to explain this intrinsic structure, we must resort to a structured ontology where entities are also constituted by their relations, including the relations Bhaskar designates as superposition and intraposition.

The stratified conception we arrive at shares many similarities with an evolutionary ontology. While in a stratified ontology we privilege the synchronic point of view, seeing higher processes constituted by lower-level processes, evolutionary theory privileges the diachronic point of view, arguing that lower-level processes evolved towards higher-level processes in a process of development towards greater complexity, going from atoms towards mole-

17 Campbell 1965.

18 Bhaskar 1997.

19 Bhaskar 1993. 
cules, cells, humans and societies. But in both cases reality constitutes a hierarchy of relational structured processes.

\section{Aristotle's Four Causes}

Having argued that reality is a hierarchy of structured processes of various degrees of superposition and intraposition, a crucial question to address is the relation between the various structured processes that populate reality, and the hierarchical levels in which these individual structured processes, such as atoms, molecules, cells, human beings and societies, are placed. Since the present article is essentially concerned with social structures, only one of these relations will be addressed, namely the relation between human agents, and the social structures that emerge from human interaction, which is the central issue of Harré's criticism of critical realism.

Social structures include a network of internally related social positions, each attached to social rules, and materialized in the social practices through which social structures are actualized and reproduced, as human agents slot into social positions engaging in social practices. Although human agents and social structures are ontologically distinct, at a further level of complexity (at a higher hierarchical level) human agents placed in a social structure constitute a totality, which is a society. For social entities such as meaning and rules cannot be understood in any way other than as constitutive of the human agent. Rules cannot be explained by rules without leading to an infinite regress, since:

As Wittgenstein remarked of the seemingly indefinite regress of rules legitimating action, the regress must end with some such declaration as 'this is simply what I do!' (Wittgenstein, 1953: §217). To adopt this way of acting is not just a rule of practice, but constitutive of my way of life. ${ }^{20}$

In fact, since rules emerge through a structured process which is the continuous interaction of human agents that takes place through social practices, it is practice (within a community, organization or society) that gives meaning to rules, and not the other way around, as Wittgenstein notes. ${ }^{21}$ Social rules, attached to various social positions within a social structure, are the underlying condition of possibility for the routinized behaviour we observe in social practices, but social rules are nevertheless ontologically distinct from social practices. In fact, a social practice may not conform exactly to a given social rule, with the latter still having causal efficacy, such as in the case of driving,

20 Harré 2009, 141.

21 For a useful discussion, see Bernasconi-Kohn 2007. 
where drivers often do not conform to rules concerning speed limit, but are nevertheless influenced by the latter. ${ }^{22}$

Paul Lewis, drawing upon the work of Bhaskar, suggests that social structures, embodied in societal human practices, can be seen as Aristotelian material causes, while human agents play the role of an Aristotelian efficient cause. ${ }^{23}$ Human agents use social structures, which are materialized in societal human practices, as a material that enables them to undertake action, but the action depends on the efficient causation of human activity.

Peter Manicas argues that the solution Bhaskar and Lewis suggest does not provide an exact analogy of the Aristotelian example where the sculptor is the efficient cause who uses marble as a material cause, since the marble is independent of human activity and thus (can be seen as a powerful particular that) can have causal powers, while social structures are continuously dependent upon human activity, and thus cannot be seen as having causal powers independently of human activity. ${ }^{24}$

However, one can make the analogy between the emergent entity (marble or social structures), and the respective agent from which it emerges (atomic or molecular agentive entities in the case of marble, human agents in the case of social structures), instead of making the analogy between the pair marble and human agents on the one hand, and the pair social structures and human agents on the other hand. ${ }^{25}$

The marble emerges as an entity (from lower-level agents like atoms and molecules) with several properties, such as solidity, which qualify it as a material to be used, just as social structures also emerge as an entity with properties that enable it to be used as a material cause for human agency. To say that social structures do not possess causal powers because they depend upon human agency would be akin to saying that marble does not have causal powers because it depends upon lower-level agentive (molecular) entities.

Aristotle's notion of material cause can be used within this framework as a way to designate an emergent entity seen from the point of view of its emergent properties. When Aristotle refers to marble as a material cause, he refers essentially to an entity that possesses various emergent properties, such as solidity, which can be taken as given for the purpose of the sculptor without the latter needing a scientific description of how they emerge from the atomic or molecular level. Likewise, Bhaskar refers to social structures as material causes to denote an entity that can be taken as given by a given

\footnotetext{
22 Lawson 2003, 37.

23 Lewis 2000; Bhaskar 1998.

24 Manicas 2006, 72-73.

25 Martins 2009a, 335-40.
} 
human agent, without the latter needing to know how it emerged from the interaction of various agents endowed with given habits and dispositions. If asked about the rules followed, the human agent would just say 'this is simply what I do!'26

Therefore, the Aristotelian notion of formal cause captures an entity from the point of view of its structure, abstracting from its emergent properties, while the notion of material cause captures an emergent entity with a set of properties, abstracting from the underlying structure. The identity of this entity is, however, ensured by a given form, which in a spatio-temporal perspective can be seen as a structured process. The notion of efficient cause captures the connection of an entity to the other structured processes that constitute and activate it by superposition and intraposition, while the notion of final cause captures how this entity may in turn be constitutive of other structured processes, that is, it refers to the role or function the entity plays in a broader context.

Effectively, if the notion of final cause is interpreted as the form towards which an entity tends, we will reach the conclusion that the notion of formal cause applied to a temporal dimension suggested above will already include the concept of final cause. The concept of process as the spatio-temporalization of structure entails that internal relations are not only synchronic, but also diachronic (that is, a given structured process can be seen as a given totality through both space and time). The concept of final cause, when interpreted as denoting an exemplar towards which a given entity tends, captures the idea of an internal relation in the temporal dimension.

The concept of final cause, seen as the role or function an entity plays in a broader context, on the other hand, is a broader interpretation that encompasses the interpretation of final cause as an exemplar towards which an entity tends, since it also helps us to understand why a given form is actualized. However, if we want to undertake our analysis at a more specific level, we still need a more specific model to explain why some forms are actualized and others are not. I will now argue that a more specific model of evolutionary selection will help explain why some forms are actualized while others are not. The general insight is that forms are selected as they are actualized in specific practices, in an evolutionary process.

\section{Final Causes and Evolutionary Processes}

The concept of final cause has been developed within critical realism by authors such as Ruth Groff and Stephen Pratten. Groff focuses on situations

$26 \quad$ Wittgenstein 1963, $§ 217$. 
where human reasons act as causes, for example when a plan is formulated and implemented in human practice. Thus, Groff notes how reasons act as final causes in this context. ${ }^{27}$

However, human interaction may also lead to unintended consequences, which nevertheless constrain or facilitate certain types of behaviour. Can the notion of final cause still play a role in such cases, where unintended consequences shape human activity? Pratten argues that the notion of final cause need not be seen in a teleological way, and can be interpreted using Charles Darwin's evolutionary framework. Pratten argues:

The theory of natural selection does not provide a mechanical explanation since it seeks to explain a particular set of processes by referring to the general types of outcome toward which they tend. ${ }^{28}$

Pratten draws the implications of this distinction to the debate between Harré and critical realism, resorting to Charles Peirce's understanding of final causality:

Harré is right to emphasize that there are two kinds of process. There are mechanical processes that relate particulars to other particulars. Mechanistic explanations are characterized precisely by the attempt to explain particular outcomes by citing particular conditions. But there are other non-mechanistic processes. There are processes with variable particular steps but which have a constant type of result. In explaining such processes reference to the general type of outcome is indispensable. It is the type selected for that explains the item selected: it was selected because it is, or has effects of, that type. Harré thinks these different processes mark out different orders only one of which is causal. From the perspective offered by Peirce's defence of the classical theory of final causality we can see that Harré, despite all his efforts, does not ultimately broaden out the notion of causality enough. Critical realists suggest that causal explanations can be applied very broadly to a variety of processes but without explaining how general types - mere possibilities - can be causes. From Peirce's perspective we can see that the distinction that Harré is pointing to is between causalities. Non-mechanical processes where you have constancy in consequence require reference to final causes in order to be adequately explained. ${ }^{29}$

So we can identify two types of final causality, which may be termed creative causation, which happens when reasons act as final causes in the sense that they provide a plan that is implemented in practice - in line with Groff - and evolutionary causation, which happens when the social environment pressures human practices in a given direction in a non-teleological way - in line with Pratten.

27 Groff 2004.

28 Pratten 2009, 208.

29 Pratten 2009, 209. 
Evolutionary explanation also helps us to conceptualize the causal role of social structures in a specific type of social process. Social structures constitute an underlying form that is actualized or materialized in social practices, and provide a material cause for the efficient causality of human agency regardless of whether it is materialized or actualized in every specific circumstance. To the extent that human action is shaped by the general environment of social practices, final causality operates through the selection of social practices that materialize certain social rules. In this sense, an evolutionary explanation of the causal role of the environment of social practices helps us to address Harré's criticism of the causal role of social structures, but stresses a type of social process where the environment exercises selective pressure (as a coercive power), thus addressing also Harré's claim that critical realism fails to provide a model that addresses the topic of human emancipation.

Evolutionary explanation, when stressing selective pressure of an environment, provides a useful model for understanding coercive power exercised by the social structures that are actualized in a given environment of social practices. Therefore, evolutionary explanation provides a useful conceptualization of a particular type of social processes that is crucial to the critical realist theory of explanatory critique, and developed in dialectical critical realism too.

In dialectical critical realism, the concept of absence plays a key role in explaining dialectical processes in general, and constraints to well-being in particular, which must be removed by absenting absences as Bhaskar argues. ${ }^{30}$ The Darwinian theory of natural selection may be helpful to the extent that it helps identify a particular type of absence, since a specification of the general concept of absence is implicit in this theory: it is because an individual lacks something that the individual is not selected by the environment, that is, because something which is essential, given the competition faced in the environment, is absent. This means that either the environment must be transformed (in order to absent absences), or the individual will be forced to adapt to the coercive power of the environment, or excluded from the selection process.

Furthermore, an evolutionary perspective can also clarify the role that embodied dispositions play in the emergence of social rules. Harré's argument points towards the role of embodied dispositions, when arguing that: '[p] eople become members of a society ... as they acquire competence in practices recognized as correct in their local culture, that is acquire grammars, pick up schemata, scripts and so on, and are trained in good habits. ${ }^{31}$

$30 \quad$ Bhaskar 1993.

31 Harré 2009, 138-9, emphasis added. 
In fact, many authors have interpreted Wittgenstein's arguments on rules as pointing towards the role of underlying dispositions. In his notion of the 'habitus', Pierre Bourdieu provides an account of the role of embodied dispositions in behaviour, which addresses Wittgenstein's claims on rules. ${ }^{32} \mathrm{John}$ Searle also argues that much of Wittgenstein's later writings were about what Searle calls the 'Background', i.e., a series of non-conscious dispositions and capacities that enables conscious states. ${ }^{33}$ An evolutionary perspective will also help to address the relationship between embodied dispositions and social structures, and the role they play in coercive power too. It is in the conceptualization of human dispositions, social structures, and their role in coercive power, that evolutionary explanation, and Lawson's PVRS (Population-Variety-Reproduction-Selection) model, to be explicated in the next section, will prove most useful.

\section{Realism and Analogy}

Bhaskar and Lawson argue that the biological realm can be seen from three different perspectives: as an existential basis for social activity, as in causal interaction with social activity, and as the source of a model to understand social activity. ${ }^{34}$ The first and second perspectives emphasize the interrelationship between the biological and social realm, and the ontological priority of the former (the biological realm is a necessary condition for the existence of social activity, but not vice-versa).

The third perspective mentioned above means that biology can provide a framework that fruitfully illuminates social processes. This approach contrasts with attempts of sociobiological reductionism, which lead to the neglect of the role of emergence. Nevertheless, in addition to the dangers of biological reductionism, there is also the possibility of universalizing, through the use of analogy, a particular model that may not be adequate to all social processes. Lawson argues that this problem with the use of evolutionary theory in social analysis, for example in evolutionary economics, springs from a lack of attention to ontology:

$[\mathrm{M}]$ odern economics is marked by a widespread committal of the epistemic fallacy. This consists in the view that questions about being can always be reduced to questions about our knowledge (of being), that matters of ontol-

32 Bourdieu 1977, 1990a, 1990b.

33 Searle 1995. See Bernasconi-Kohn 2007, or Lawson 2003, 45-6, for a discussion of Bourdieu's 'habitus', and Manicas 2006, or Martins 2009a, for a discussion of the relation between Searle's 'Background' and critical realism.

34 Bhaskar 1986; Lawson 2003, 113. 
ogy can always be translated into epistemological terms. This fallacy assumes the form of an expectation that methods can be adopted from any sphere, and/or be of any kind - mathematical, evolutionary or whatever - and successfully applied irrespective of the nature of the object of study (see Lawson 1997). Even in the more insightful discussions bearing upon the possibility of an evolutionary economics, questions of ontology have tended to be obscured by a concentration on other matters. The latter have included such issues as whether Darwin consistently proposed one sort of evolutionary theory or mechanism only, the proper interpretation and relevance of the contributions of Lamarck, the nature of frontier modelling in modern biology, and so forth. Whilst these sorts of inquiries have their interest, they easily distract from those more relevant to the question of whether it is feasible in any useful way at all to abduct from biology into social theory. In any case, whatever the reason for it, questions of ontology have been largely neglected in discussions of borrowing from others, and here my purpose is to help rectify this situation. It is the case that ontological considerations of some sort do already creep in here and there. However, they rarely do so in a sufficiently explicit and systematic fashion. My limited aim here, as I say, is to contribute to helping redress this situation. ${ }^{35}$

In fact, most contributions to the use of evolutionary theory in social analysis still seem to see structures as a property of the theories about reality, rather than of reality itself. Hence, prominent authors in evolutionary analysis such as Geoff Hodgson argue that it is necessary to move from analogy to ontology. ${ }^{36}$ However, while authors such as Hodgson and Knudsen argue that the social realm does conform to the Darwinian description of the biological realm, Lawson argues that evolutionary models, and models of natural selection in particular, can be seen as a particular case within the general description of social processes given by the transformational model of social activity. ${ }^{37}$ Lawson writes:

[I]f this transformational model allows that both transformation and reproduction occur, it says little about either the conditions wherein one or the other is likely to dominate, or the specifics of any processes of social reproduction/transformation. The 'natural selection' model then, if appropriate at all, will presumably indicate one specification of the transformational model. It will provide a more concrete account of how reproduction and/ or transformation of specific aspects of social structure can happen. ${ }^{38}$

If we see evolutionary models as any model that uses the notion of structured process discussed above, we have a general enough conception that applies both to the social and the biological realm. However, if we resort to more spe-

\footnotetext{
35 Lawson 2003, 111-12.

36 Hodgson 2002.

37 Hodgson and Knudsen 2006.

38 Lawson 2003, 126.
} 
cific models, such as the natural selection model, we are using a framework that is suited for particular cases only, but whenever appropriate, will provide a more specific account than the transformational model of social activity. ${ }^{39}$

For example, the natural selection model will be best suited to explain the pressure of the social structure on human activity, rather than purposeful activity where reasons act as final causes, such as in the cases discussed by Groff. ${ }^{40}$ In this context, Lawson develops his PVRS (Population-VarietyReproduction-Selection) model, which is aimed at explaining social reality at a more specific level, and helps to address the topic of human emancipation by providing a more specific explanation of coercive power and of the causal role of social structures, the central topics in Harré's critique of critical realism.

\section{The PVRS Model}

A central distinction for the formulation of the PVRS model is the distinction between interactors and replicators. Interactors are the entities that compete in the environment of selection. ${ }^{41}$ The entity that passes on its structure (i.e., is reproduced) in the evolutionary process will be termed here the replicator. ${ }^{42}$ Once this distinction is made, we can combine it with the central elements of Darwin's evolutionary theory, and his notion of natural selection in particular, in order to formulate the PVRS model. ${ }^{43}$

Lawson defines his PVRS model as a model that contains five essential features: a population of interactors; a variety of replicators (which depends upon an underlying variety-generating mechanism); a replication mechanism through which replicators are reproduced; a selection mechanism through which the interactor is selected in the environment, and some degree of independence between variety-generating mechanisms and selection mechanisms. ${ }^{44}$ Note that although we are ultimately analysing which replicators are selected, this selection happens through the interactor that corresponds to each replicator.

In evolutionary biology, interactors are located in, or in fact consist in, the individual organisms that compete in the environment of selection. The

\footnotetext{
39 For a discussion of the connections between the transformational model of social activity and evolutionary theory, see also Martins 2009b.

40 Groff 2004.

41 Hull 1981.

42 Dawkins 1976, 1978.

43 Darwin 1859, 1872.

44 Lawson 2003, 121-3.
} 
genetic characteristics of individual organisms constitute the entity that is replicated, designated as the genotype. The genotype (i.e., the replicator in evolutionary biology) endows each individual organism with given (phenotypic) characteristics, which contribute to the greater or lesser fitness of the interactor. A question that naturally follows is which entities we should regard as replicators and interactors in the social realm.

Note that while most evolutionary theorists formulate their models by universalizing the analogy with the biological realm, a more suitable endeavour is to formulate an evolutionary model where the structures identified are a property of reality, and not of the theories used to analyse such reality. While analogy is surely helpful to guide our thinking, realist evolutionary analysis must be undertaken a posteriori, informed by an ontological analysis of reality (for example, by the transformational model of social activity, which is achieved through a posteriori ontological analysis), and not through an a priori epistemological generalization of a biological analogy. The question that follows concerns which social entities exist already in competition in reality, and which social entities maintain a stable relationship with the interactors throughout social activity, endowing the latter with a given level of fitness or competitiveness. Lawson argues:

In keeping with the transformational model, then, I would suggest that the most promising, or anyway one conceivable, candidate for the social interactor is social practice, and the environment of selection includes all other social practices that are in some way related or connected to that population of practices that constitutes our primary focus. Interaction with the environment just is human interaction. What sort of thing or aspect might be interpreted as a social replicator, the entity that passes on its structure in replication? The answer that fits most easily with the transformational conception of social activity, I suggest, is social structure, and especially social rules including norms and conventions. ${ }^{45}$

So social practices are the social interactors, and social structures, including social rules, are the social replicators that are selected (or not) through the competition of social interactors. This specification of social interactors and social replicators is the defining characteristic of Lawson's PVRS model.

Let us focus on the social replicators first. Lawson takes a very broad conception of social rules, and in fact suggests that it is not just rules, but social structures in general, that can be seen as replicators. Lawson defines rules as generalized procedures for action of the form 'if $\mathrm{x}$ do $\mathrm{y}$ under conditions $z$ ' ${ }^{46}$ The social rule, i.e., the entity that is replicated, assumes thus a form 'if $\mathrm{x}$ do $\mathrm{y}$ under conditions $\mathrm{z}$ ', which can be actualized in actions, habits, and

45 Lawson 2003, 128.

46 Lawson 1997, 162. 
observable behaviour in general, and is enabled by underlying dispositions and potentials, which are nevertheless distinct (transfactual) entities from the observable behaviour (including actions, habits and routines) that presupposes them.

The term disposition can be used to denote the potential or tendency to engage in any form of observable behaviour. Such potential is enabled by underlying structures - examples are neurobiological structures, or social structures. Following Lawson, I distinguish the disposition (or potential) for engaging in observable behaviour from habitual action or routines, which will be taken to consist in (repeated patterns of) observed behaviour. ${ }^{47}$

Lawson notes that a social rule can be seen as a 'code, convention, or understanding about how an act could or should be performed', where such code can be followed tacitly or consciously. ${ }^{48}$ Hence, the replicators or social rules in Lawson's PVRS model can be taken in a broad sense, including also ideas, techniques and any type of entity that may embody codified information of the form 'if $\mathrm{x}$ do $\mathrm{y}$ under conditions z' - where 'do y' can be taken in a broad sense, for example taken to mean 'interpret as y'. In fact, the essential feature of a replicator in an evolutionary model is that it consists in, or contains, a code that is transmitted through the replication mechanism (in evolutionary biology the replicators are the underlying genetic code or information of the interactor). The code 'if $\mathrm{x}$ do $\mathrm{y}$ under conditions $\mathrm{z}$ ' is the codified information that is replicated here, and this codified information is a form that becomes actualized in observable entities or practices.

Now let us consider Lawson's choice of social practices as the social interactors. Social practices are enabled by social, technological and psychological structures, and include the actualization of any of these structures of rules or codes as actual practices. Of course, such codes or information will often be combined with a material basis. Social rules, conventions, ideas and techniques can be materialized in books, artefacts or any means of recording codified information, and not just in the social practices (the interactors) in which they are actualized - and Darwin himself made the remark that the written books left by the Greeks contributed more to the evolution of western culture than their genetic characteristics. ${ }^{49}$

The question one could ask is whether another interactor could have been chosen. For example, human individuals, organizations and technologies can also be selected in an evolutionary social process. But note that Lawson's formulation can still encompass a situation where it is an individual, organi-

47 Lawson 2003, 233-4.

48 Lawson 2003, 37.

49 Darwin 1872. 
zation or technology that is selected. For there are two ways through which the selection environment - the population of competing social practices can cause the selection of social practices in Lawson's formulation. The first type of selection, which will be termed here vicarious selection, is by causing (or even forcing) individuals or organizations to keep or to change their social practices (or at least influencing them to do so).

The term vicarious selection is used here in the same sense as that described by Donald Campbell. ${ }^{50}$ Vicarious selection enables us to take into account the fact that social structures often exercise their power in shaping human action without eliminating particular individuals. Social structures are a material cause for human agency even when agents are not selected in every specific circumstance where they have a causal role, and have thus a crucial effect on human well-being even when not eliminating human agents in every particular instance. ${ }^{51}$

In vicarious selection, social practices (including the performance of given techniques that rely on corresponding technologies) are selected directly through the decisions of individuals or organizations that choose to keep or to abandon given social practices, but choose so because the environment of selection leads them to do so (and in many cases forces them to do so, acting as a coercive power). Because social practices are selected directly through decisions, vicarious selection may also be termed as direct selection of social practices.

The second type of selection, to be termed here natural selection, following Darwin's usage of the term, consists in selecting or excluding those individuals or organizations that engage in given social practices (for it may well be the case that people or organizations decide to maintain given social rules, ideas or techniques regardless of how favoured they are by the environment of social practices).$^{52}$ In this second case, social practices (again, including the performance of particular techniques that rely on corresponding technologies) are selected indirectly, through the selection of the individuals or organizations that reproduce them, and so this type of selection can also be termed indirect selection of social practices.

In both cases, the replicated code or information is selected through the selection of the social interactors (viz., social practices), but only in the latter case are human individuals or organizations also themselves selected. In both cases, it is the competitive pressure of the environment of selection that

\footnotetext{
50 Campbell 1965.

51 See Martins 2007, 270-2, for a discussion with special reference to the impact of social rules, as material causes, on human well-being.

52 Darwin 1859.
} 
makes individuals change their decisions, or excludes them if they do not change their decisions. Natural selection refers to the selection of entities such as individuals or organizations (including a whole society, if we assume a population of societies), and thus of the corresponding codes, structures or forms that are embodied in them, while vicarious selection reflects a change in the structure of an organization (or society) caused by the pressure of the environment of social practices on the decision of human individuals.

Note that, because of the particular specification used by Lawson in the PVRS model, we cannot take vicarious, or direct, selection, to have exactly the same meaning that adaptation has in evolutionary biology. Because the interactor is the social practice and not the human agent, a deliberate change of social practice is a case of (vicarious or direct) selection, and not of adaptation, which would be a change in the interactor, not a selection of the latter.

Note also that a stable correspondence between replicator and interactor is essential for any explanatory framework based on the selection principle. For if an interactor could change its replicator at any moment, it would become difficult to distinguish evolutionary change from other types of change, and an epistemological problem of identification of replicators would arise.

The possibility that codes and rules may change through vicarious selection means that, in such a case, there may not exist a stable correspondence between replicators on the one hand, and human individuals or organizations on the other hand, for vicarious selection occurs precisely when the latter decide to change their codes and rules. A stable correspondence between replicators on the one hand, and human individuals or organizations on the other hand, exists only in what is termed here as natural or indirect selection (since in such a case individuals or organizations maintain their codes and rules).

If human individuals or organizations were taken to be the interactors, as in most evolutionary social theory, one would have to assume a stable correspondence between individuals or organizations on the one hand, and rules (i.e. replicators) on the other hand - in order to avoid the epistemological difficulties that would spring from the possibility that interactors may change their replicators. But to assume a stable correspondence between individuals or organizations on the one hand, and rules (i.e., replicators) on the other hand, would lead to a model where only natural or indirect selection exists, and would preclude the possibility of conscious decision-making of agents who intend to change their rules, i.e. would preclude the possibility of the process termed here vicarious selection - when human individuals or organizations decide to change their replicators (even though such change is not always easy, it does occur). So the PVSR model provides an evolutionary conception which does not place artificial constraints on reality, such as assum- 
ing that individuals or organizations cannot change their rules and practices, precisely because, unlike much evolutionary theory, it is derived a posteriori informed by ontological analysis, and not a priori through an uncritical universalization of the biological analogy.

Thus, in the PVRS model, for a code to be replicated, it has to be the case that an individual decides to keep practising a given social rule, and that this individual is not selected out (through a process of natural, or indirect, selection). Also, if the capability to perform such social rule is provided by a given organization, then such an organization must maintain the social rule as a social practice, and the organization must also be itself favoured by (natural or indirect) selection in order for the social practice to continue.

We can already see that a particular situation in which the PVRS model is particularly useful in social analysis concerns the conceptualization of the role of the environment of selection in constraining our actions. While in the transformational model of social activity social structure is seen as facilitating or constraining human agency in more abstract terms, the concept of environment of selection refers to a concrete actualization of a social structure (which comprises the social replicators, viz., social rules) in a specific environment of social practices, which exerts competitive pressure through a selective process of competition within a population of social practices. In this sense, the PVSR model may be particularly fruitful in the critical realist theory of explanatory critique, in order to understand processes where, through vicarious or natural selection, coercive power is exercised.

\section{Distinguishing between Selection Mechanisms, Replication Mechanisms and Variety-Generating Mechanisms}

The role of underlying dispositions on behaviour can also be conceptualized using the PVRS model. Human agents, and the organizations in which they are placed, can be seen as possessing three different sets of capacities or dispositions: (i) capacities or dispositions to action and creativity; (ii) capacities or dispositions to maintain their structures and functionings in a relatively stable manner in relation to changes in the environment; and (iii) a capacity to respond to changes in the environment. These capacities or dispositions will support: (i) variety-generating mechanisms; (ii) replication mechanisms; and (iii) selection mechanisms, respectively. In a Darwinian framework, variety-generating mechanisms and replication mechanisms are relatively independent from changes in the environment of selection, while selection mechanisms are those triggered primarily by changes in the environment of selection, and denote the competitive pressure caused by the latter. 
Concepts like dispositions and habits, which Harré, like Bourdieu, Searle and critical realists, argue to be fundamental notions for the development of a theory of social and psychological development, can then be analysed in terms of the role they play in generating variety, replication and selection, taking into account the way in which these processes will in turn shape dispositions and habits. These notions are also crucial to the understanding of how societies and organizations emerge, and the rules and routines that structure societies and organizations.

Now, even though some distinction between selection mechanisms and variety-generating mechanisms is necessary for Darwinian analysis, it is also the case that these mechanisms may be to some extent interdependent. In what Lawson calls a strictly Darwinian framework, the variety-generating mechanism (or the variety of traits) is regarded as independent from the selection mechanism. So, in a strictly Darwinian model, the dispositions that influence the replication and variety of social rules are independent from the environment of selection - i.e., from the competing social practices. ${ }^{53}$

When the environment of selection has some sort of causal influence on the variety-generating mechanism, Lawson names the evolutionary process a Lamarckian process. ${ }^{54}$ In biology, following Jean-Baptiste de Lamarck, Lamarckian models refer to situations where acquired traits are inherited, in order to represent the case where the selection environment may influence the variety-generating mechanism, and hence the traits that are produced and selected (in biology, this means it influences the genetic features of the individual organism taken to be the phenotype, or displaying phenotypic characteristics). But a formulation where the interactors are social practices leads us to define a Lamarckian model as Lawson does: a model where the selection environment influences the variety traits. For the general insight behind the traditional formulation of the Lamarckian model as one where acquired traits are inherited is that the selection environment may influence the variety-generating mechanism, and thus influence the traits that are produced and selected.

In a Lamarckian model, the environment of selection causes a change indirectly through its influence on the variety-generating mechanism, i.e. the environment of selection first changes the underlying replicators, and then selects the interactors that reflect the modified replicators. This second step is crucial, for when a disposition to act according to a different code, rule or technique is generated by the variety-generating mechanism, it will not necessarily be manifest in actual behaviour as a social practice, for it still needs

53 Lawson 2003, 123-4.

54 Lawson 2003, 124. 
to be selected by the relevant mechanism, in the environment of competing social practices. The fact that a variety of codes, rules or techniques is generated (for example, because a tendency or disposition to adopt new codes, rules or techniques arises) does not imply that such variety will be materialized in actual social practices, for the selection mechanism might prevent it.

Moreover, human agents may deliberately decide to change the environment of selection, engaging in creative activity that generates a new environment. This is the case where final causes are just reasons, as Groff argues. ${ }^{55}$ In fact, the causal forces linking variety-generating mechanisms and selection mechanisms can work in the opposite direction. Relationships of power and authority between entities signify that the variety-generating mechanism may be able to influence the environment of selection, by generating new codes and rules, and directly imposing them upon the environment.

So we have a strictly Darwinian process when the selection environment and variety traits are independent, a Lamarckian process when the selection environment influences variety traits (for example, influences human dispositions), and a creative process when the variety-generating mechanism (for example, human creativity) changes the environment of selection. As Lawson notes, Darwin himself was open to the possibility of change caused by mechanisms other than natural selection, even in the biological realm, for in the final edition of The Origin of Species, Darwin writes:

But as my conclusions have lately been much misrepresented, and it has been stated that I attribute the modification of species exclusively to natural selection, I may be permitted to remark that in the first edition of this work and subsequently, I placed in a most conspicuous position - namely at the close of the Introduction - the following words: 'I am convinced that natural selection has been the main but not the exclusive means of modification'. This has been of no avail. Great is the power of steady misrepresentation. ${ }^{56}$

So the attempt to advocate 'Darwinism', understood as the theory of natural selection, as a universal theory to be applied to all domains of reality, seems to spring from a misrepresentation of Darwin's original contribution. ${ }^{57}$ Furthermore, not only does the project of Universal 'Darwinism' misrepresent Darwin, it also either engages in the epistemic fallacy, by placing structures in the epistemological domain, or presupposing a priori an ontological similarity between different (emergent) levels, such as the biological and the social realm.

55 Groff 2004.

56 Darwin 1872, 421, as cited in Lawson 2003, 112.

57 Prominent accounts of Universal Darwinism can be found in Dawkins 1983, or Dennett 1996, for example. 
On the other hand, a version of natural selection models that is generalized enough so as to accommodate all types of social phenomena loses the specificity which, Lawson argues, is the added-value that natural selection models could bring to social analysis, and leads us to a model which does not give us anything further than what the transformational model of social activity already provides. This is why Lawson notes that models of natural selection in the context of social analysis, including his own PVRS model, can be most usefully seen as particular specifications of the transformational model of social activity, and not as a universal theory. As noted above, a particular situation to which the PVRS model could be applied in social analysis constitutes situations of coercive power.

Coercive power may be conceptualized in the PVRS model as an unintentional selective power, exercised by the selection environment, which can be conceptualized as a power to select social practices, individuals or organizations (through Darwinian selection), to force changes in dispositions (the case of Lamarckism). But coercive power can also be seen as an intentional power to change the environment of selection, that is enabled by the creative capacities of human beings, where this new environment may in turn exert coercive power. Within a broad transformational conception, we can identify Darwinian, Lamarckian and creative processes as particular types of processes, depending on the relation between the environment of selection and the human agents.

Furthermore, not only is it the case that Universal 'Darwinism' seems to overemphasize natural selection, but even its conceptualization of selection itself is restrictive. In fact, the PVRS model enables the use of an evolutionary model to understand processes where other specifications of Darwinian processes would fail. For example, David Hull, when addressing Richard Dawkins's conception of memetics in particular, argues that cases of transmission of ideas (like cases of contagion) cannot be defined as Lamarckian, because although there is a change in the phenotype that adopts the ideas transmitted (which are the genotypes or replicators), the new characteristics are not selected through the competition of phenotypes. ${ }^{58}$

If we follow Hull here, the process of transmission of ideas would in fact not even be one of natural selection, nor even a Darwinian process, precisely because there is no competition of phenotypes. On the other hand, if the interactor is the social practice that corresponds to the social rule or idea, as in the PVRS model, there can still be competition between the social practices in cases of transmission of ideas by contagion, such as those addressed by Hull, and evolutionary analysis can fruitfully illuminate the dynamics of this process.

$58 \quad$ Hull 1982, 2000. 


\section{Concluding Remarks}

An account of emergence using process as the central ontological category, which is present in many evolutionary theories, enables us to conceptualize societies as entities with the same ontological status as atomic, molecular, cellular and organic structures. The idea that evolution progresses towards greater complexity also provides a diachronic analogue to the synchronic coexistence of various hierarchical levels of emergent structured processes.

Furthermore, Aristotle's four causes can be fruitfully used to understand emergence, process and structural causality. Aristotle's formal cause focuses on the structure of an entity, while Aristotle's material cause emphasizes the emergent properties of an entity, such as social structures, while abstracting from the lower-level structured processes that generate it. Efficient causation depends upon the activity of the relevant agent at a given level of analysis the human agent in social analysis, as Harré notes - while Aristotle's final cause may consist in human reasons when agents plan and execute an action, or can be understood resorting to evolutionary analysis when explaining non-teleological processes. This framework provides an emergent account of structural causation that allows for a conceptualization of the causal role of social structures.

A particularly useful evolutionary theory for the conceptualization of underlying dispositions, and the coercive power of social structures, which is a central topic in Harré's critique, is given by Lawson's PVSR model, in which the environment of social practices provides an actualization of the underlying social structures through which structural causation takes place, both when human agents are themselves selected and when they are not (the case of vicarious selection).

Lawson himself applies the PVRS model to a similar context, namely to explain the pressure towards a mathematizing tendency in the social sciences, caused by the cultural and academic environment. Thus social situations of coercive power, where a given environment pressures human agents to act in a given way, seem to be a particular type of situation in which the PVRS model has a higher explanatory power. In this sense, it may play an important role in the critical realist theory of explanatory critique, and in the identification of the social structures that constrain human well-being through vicarious selection and natural selection.

Following Lawson, interactors were defined as social practices (including the performance of techniques). This specification enables Lawson's model to conceptualize human agents (the causal power that sets social and technological structures into motion) as active and creative entities that can change their decisions. Evolutionary models that conceptualize the human agent (or 
organizations) as the social interactors are often faced with the problem that an interactor must contain a stable replicator, and hence face difficulties in conceptualizing human creativity and innovation (including the creativity displayed by human agents within organizations).

Because social practices are specified as the social interactors here, the correspondence between replicators and interactors is here maintained without the creativity of human agents being neglected. Furthermore, within the framework of the PVRS model we can identify Darwinian, Lamarckian and creative processes as three particular types of transformational processes. All these constitute types of final causation.

Analogies like the biological analogy may be most useful in social theory. But the psychological and social structures that a social theory identifies are best seen as an ontological constituent of reality, which is permanently reproduced through the human practices that presuppose it, where the latter are of course the source of meaning of the rules and conventions reproduced within a community.

\section{Bibliography}

Bernasconi-Kohn, L. 2007. 'Wittgenstein and the ontology of the social: some Kripkean reflections on Bourdieu's "Theory of Practice"'. In Contributions to Social Ontology, eds C. Lawson, J. S. Latsis and N. Martins, 68-88. London: Routledge.

Bhaskar, R. 1986. Scientific Realism and Human Emancipation. London: Verso.

Bhaskar, R. 1993. Dialectics: The Pulse of Freedom. London: Verso.

Bhaskar, R. [1975] 1997. A Realist Theory of Science. London: Verso.

Bhaskar, R. [1979] 1998. The Possibility of Naturalism. London: Routledge.

Bhaskar, R. 2007. 'Theorizing ontology'. In Contributions to Social Ontology, eds C. Lawson, J. S. Latsis and N. Martins, 192-204. London: Routledge.

Bickhard, M. H. 2000. 'Emergence'. In Downward Causation, eds P. B. Andersen, C. Emmeche, N. O. Finnemann and P. V. Christiansen, 322-48. Aarhus: University of Aarhus Press.

Bourdieu, P. 1977. Outline of a Theory of Practice. Cambridge: Cambridge University Press.

Bourdieu, P. 1990a. In Other Words. Cambridge: Polity.

Bourdieu, P. 1990b. The Logic of Practice. Cambridge: Polity.

Brown, H. R. and R. Harré. 1988. Philosophical Foundations of Quantum Field Theory. Oxford: Oxford University Press.

Campbell, D. 1965. 'Variation and selective retention in socio-cultural evolution'. In Social Change in Developing Areas: A Reinterpretation of Evolutionary Theory, eds H. R. Barringer, G. I. Blanksten and R. W. Mack, 19-49. Cambridge, MA: Schenkman.

Darwin, C. R. 1859. On the Origin of Species by Means of Natural Selection, or the Preservation of Favoured Races in the Struggle for Life. London: John Murray.

Darwin, C. R. [1859] 1872. The Origin of Species by Means of Natural Selection, or the Preservation of Favoured Races in the Struggle for Life, 6th edn. London: John Murray.

Dawkins, R. 1976. The Selfish Gene. Oxford: Oxford University Press.

Dawkins, R. 1978. 'Replicator selection and the extended phenotype'. Zeitschrift für Tierpsychologie 47: 61-76. doi:10.1111/j.1439-0310.1978.tb01823.x

Dawkins, R. 1983. 'Universal Darwinism'. In Evolution from Molecules to Man, ed. D. S. Bendall, 403-25. Cambridge: Cambridge University Press. 
Dennett, D. C. 1996. Darwin's Dangerous Idea: Evolution and the Meanings of Life. London: Penguin.

Groff, R. 2004. Critical Realism, Post-positivism and the Possibility of Knowledge. London: Routledge.

Harré, R. 2009. 'Saving critical realism'. Journal for the Theory of Social Behaviour 39: 129-43. doi:10.1111/j.1468-5914.2009.00403.x

Harré, R. and E. H. Madden. 1975. Causal Powers: A Theory of Natural Necessity. Oxford: Basil Blackwell.

Hodgson, G. M. 2002. 'Darwinism in economics: from analogy to ontology'. Journal of Evolutionary Economics 12: 259-81. doi:10.1007/s00191-002-0118-8

Hodgson, G. M. and T. Knudsen. 2006. 'Why we need a generalized Darwinism and why a generalized Darwinism is not enough'. Journal of Economic Behaviour and Organization 61: 1-19. doi:10.1016/j.jebo.2005.01.004

Hostettler, N. 2000. 'Did Ludwig Wittgenstein really understand Roy Bhaskar?' Alethia 3: 22-8.

Hull, D. 1981. 'Units of evolution: a metaphysical essay'. In The Philosophy of Evolution, eds U. J. Jensen and R. Harré, 23-44. Brighton: Harvester.

Hull, D. 1982. 'The naked meme'. In Learning, Development and Culture: Essays in Evolutionary Epistemology, ed. H. C. Plotki, 273-327. New York: Wiley.

Hull, D. 2000. 'Taking memetics seriously: memetics will be what we make it'. In Darwinizing Culture: The Status of Memetics as a Science, ed. R. Aunger, 43-68. Oxford and New York: Oxford University Press.

Lawson, T. 1997. Economics and Reality. London: Routledge. doi:10.4324/9780203195390

Lawson, T. 2003. Reorienting Economics. London: Routledge.

Lewis, P. A. 2000. 'Realism, causation and the problem of social structure'. Journal for the Theory of Social Behaviour 30: 249-68. doi:10.1111/1468-5914.00129

Manicas, P. 2006. A Realist Philosophy of Social Science: Explanation and Understanding. Cambridge: Cambridge University Press. doi:10.1017/CBO9780511607035

Martins, N. 2007. 'Realism, universalism and capabilities'. Review of Social Economy 65: 253-78. doi:10.1080/00346760701635817

Martins, N. 2009a. 'Rules, social ontology and collective identity'. Journal for the Theory of Social Behaviour 39: 323-44. doi:10.1111/j.1468-5914.2009.00406.x

Martins, N. 2009b. 'A transformational conception of evolutionary processes'. Evolutionary and Institutional Economics Review 6: 71-102.

Pratten, S. 2009. 'Critical realism and causality: tracing the Aristotelian legacy'. Journal for the Theory of Social Behaviour 39: 189-218. doi:10.1111/j.1468-5914.2009.00400.x

Searle, J. R. 1995. The Construction of Social Reality. London: Penguin.

Vygotsky, L. S. 1978. Mind in Society. Cambridge, MA: Harvard University Press.

Whitehead, A. N. 1929. Process and Reality: An Essay on Cosmology. London: Macmillan.

Wittgenstein, L. [1921] 1961. Tractatus Logico-Philosophicus, trans. D. F. Pears and B. F. McGuiness. London: Routledge \& Kegan Paul.

Wittgenstein, L. [1953] 1963. Philosophical Investigations, trans. G. E. M. Anscombe. Oxford: Blackwell.

Wittgenstein, L. 1975.On Certainty. Oxford: Blackwell. 